\title{
Autobiografia de Raízes do Brasil: rememoração e comemoração do ensaio nos anos 1970-1980
}

\author{
The Roots of Brazil's "autobiography": Remembrance and celebration \\ of the essay (1970-1980)
}

\author{
Raphael Guilherme de Carvalho \\ raphaelguilherme83@gmail.com \\ Pós-doutorando \\ Instituto de Estudos Brasileiros - Universidade de São Paulo \\ Rua Ubaldino do Amaral, 1530, ap. 11, Jd. Botânico \\ 80060-092 - Curitiba - Paraná \\ Brasil
}

\begin{abstract}
Resumo
Nesses oitenta anos de Raízes do Brasil (1936), de Sérgio Buarque de Holanda, uma das fases importantes de sua história se passou entre as décadas de 1970e 1980. Nesse período, ficouconsolidada, a partir da edição definitiva (1969), a posição do livro comoclássico da historiografia brasileira. Se desdeoinício de século 21 tem sido realizado o trabalho de cotejo das suas diferentes edições, procuro chamar a atenção para a importância de alguns elementos imanentes oucomplementares ao texto - que ainda hoje pesam sobre a recepção e a história do livro. Quais sejam: entre 1970 e 1980, as relações entre asrememorações autocríticasde seu autor, a incorporação de materiais paratextuais e as sucessivas comemorações da obra. Tais elementos também importaram, pois, no processo de recontextualização do ensaio naquelas décadas e na formação de densa camada de memória acerca de Raízes do Brasil e seu autor.
\end{abstract}

\section{Palavras-chave}

Homem Cordial; Memória; Sérgio Buarque de Holanda.

\begin{abstract}
Since the publication of "Roots of Brazil" in 1936 by Sérgio Buarque de Holanda, one of the most important periods in this book's wealth of critical acclaim happened between the 1970s and 1980s. During this time, after its definitive edition in 1969, the book was consolidated as a Brazilian historiography classic. Since the beginning of the 21st century, various editions have been compared as to their differences; my objective with this article is to call attention to the importance of some elements that - although immanent or supplementary to the text - remain influential until today to the reception and to the history of the book. They are the relations among the author's self-critical recollections, the incorporation of paratextual materials, and the successive celebrations of the work, between 1970 and 1980. These elements were also very important to the recontextualization process of the genre essay in those decades, and as well to the building of a thick layer of memories around "Roots of Brazil" and its author.
\end{abstract}

\section{Keywords}

Cordial Man; Memory; Sérgio Buarque de Holanda. 
Os escritores em idade madura não gostam de ser felicitados com muita convicção pela primeira obra.

Jean-Paul Sartre (1964 p. 195, trad. livre).

O nome de Sérgio Buarque de Holanda (1902-1982), durante quase toda sua trajetória intelectual e até hoje, permanece estreitamente identificado a seu livro de estreia, Raízes do Brasil (1936). Trata-se do seu livro mais editado, traduzido e, ainda, comentado, devido à sua complexidade e possibilidades diversas de interpretação, talvez também pela vertiginosa atualidade de alguns de seus enunciados ou, então, em razão do locus privilegiado do(s) tempo(s) em que foi produzido, "negado", revisto e, quase obsessivamente, rememorado pelo autor, além de comemorado em diversas reedições.

Desenrola-se diante do leitor atual uma gradação de interpretações de $R d B$ que se situam entre polos opostos e dificilmente conciliáveis, da afirmação de um "radicalismo democrático" (CANDIDO 1969; 1986) até a proximidade do "conservadorismo europeu" dos anos 1930 (WAIZBORT 2011; MATA 2016). Desde o início do novo século vem ocorrendo um movimento de retorno crítico à primeira edição de $R d B$ e cotejos com as demais. ${ }^{1} O$ suprassumo desse movimento é a edição crítica (HOLANDA 2016) preparada na ocasião dos oitenta anos do livro. São discriminadas todas as mudanças textuais operadas entre as cinco primeiras edições, de 1936 a 1969, e a atualidade da fortuna crítica aparece contígua ao livro em posfácios. O que se pode reter minimamente do debate é que apenas em 1948 o ensaio passa a configurar uma interpretação do Brasil em chave "progressista". Sedimenta-se, com isso, nova camada de memória sobre $R d B$.

Estudaremos, aqui, como $R d B$, já nos anos de 1970 e 1980, está situado entre história e memória. Em função de sua posição de clássico da historiografia brasileira, marco mesmo da memória da disciplina, procuro compreender, neste artigo, uma fase importante, mas praticamente desconsiderada no estudo de sua história. Realizaremos uma leitura das rememorações e autocríticas tardiasde seu autor, em relação com as comemorações da obra, além da incorporação de importantes paratextos. "Autobiografia de RdB", ${ }^{2}$ então, porque se trata de sinalar a principal preocupação da escrita de si do historiador, ${ }^{3}$ a autocrítica de seu livro de estreia, como fator considerável na história e recepção acadêmica de $R d B$.

O estudo da escrita de si dos historiadores ${ }^{4}$ pode contribuir para a autocrítica da história da historiografia, desde a percepção de como eles participam da elaboração de sua própria memória até como são por eles dispostas e mobilizadas

\footnotetext{
${ }^{1}$ Alguns dos autores que desde então têm se debruçado sobre as mudanças entre a primeira e demais edições são: Eugênio (2011), Waizbort (2011), Castro Rocha (2012), Feldman (2012), Nicodemo (2014) e Mata (2016). 2 A metáfora no título escolhido dialoga com "Raízes do Brasil: biografia de um livro-problema", de Castro Rocha (2012, p. 19-39), que se atém ao estudo das mudanças no texto de 1936 no tempo. Minha proposta que contorna as margens desse debate atual, vale precaver - se atém principalmente à leitura da autocrítica de Buarque de Holanda sobreRdB, a partir, portanto, de elementos exteriores ao texto.

${ }^{3}$ O presente artigo retoma capítulo de tese "Sérgio Buarque de Holanda, do mesmo ao outro: escrita de si e memória (1969-1986)" (cf. CARVALHO 2017).

4 Sobre a escrita de si dos historiadoresno tempo presente, seu estatuto e possibilidades heurísticas, ver Dosse (2011, p. 389-396) e Garcia (2014, p. 20).
} 
as autorrepresentações da história como disciplina (POPKIN 2005, p. 280). A partir de suportes, tais como autobiografias, memórias, correspondências, depoimentos, a crítica historiográfica ou mesmo a história da historiografia, a "memória disciplinar cristaliza momentaneamente as relações de força que se disputam em determinado campo" (MÜLLER 2005, p. 198). ${ }^{5}$

Buarque de Holanda, logo em 1948, decreta a "morte do homem cordial", mas continua muitas décadas depois ocupando-se de revivificá-lo. Os autocomentários sobre as intenções primevas de RdBse concentraram na polêmica sobre a verdadeira acepção de cordialidade como traço singular do "caráter brasileiro". Desse modo, críticas potenciais ficaram, pelo tempo, asfixiadas. Contudo, a senda aberta por diversos estudos atuais tem favorecido o descerramento de outras discussões possíveis e, assim, a pluralidade interpretativa do clássico se revitaliza contra os riscos de conformação do debate, por longo tempo consubstanciado à memória.

\section{Os estertores e a remição do homem cordial (1948-1969)}

Associada a $R d B$ como sendo a sua principal objeção, observaremos rapidamente a contenda com Cassiano Ricardo - em 1948 e tão somente por ocasião de sua segunda edição, a mais profundamente modificada, para posterior apreciação dos elementos que serão rememorados pelo autor nos anos 1970 e 1980. Em seguida, consideraremos a profunda autocrítica realizada por Buarque de Holanda em uma palestra diante dos militares em 1967, que também estabelecerá os marcos da memória de $R d B$, muitas vezes repetidos nas décadas seguintes.

Cassiano Ricardo foi seguramente o primeiro a observar, ainda que brevemente, a profundidade das mudanças operadas por Buarque de Holanda entre a primeira e a segunda edição de $R d B$ : "pretendendo explicar a palavra, Sérgio alterou, descaracterizou nosso 'homem cordial'" (RICARDO 1948, p. 45). Ricardo não se conformou que a cordialidade, na segunda edição, ganhasse maior nitidez como o oposto da polidez e se afastasse decididamente da suposição em contrário. Para ele, pois, o brasileiro se definia pelo caráter de bondade propriamente dita, "não bondade em sentido de simples cordialidade" (RICARDO 1948, p. 53).

Buarque de Holanda responde primeiro em nota na segunda edição e, logo em seguida, em três páginas muito objetivas na revista Colégio. Ele anota mesmo uma certa banalidade no debate - "nossa divergência se reduz, afinal, a uma questão de palavra" (HOLANDA 1948, p. 52). A fim de delinear algumas mudanças de posição entre "minhas antigase novasideias" (HOLANDA 1948, p. 54), ${ }^{6}$ apressa-seem decretar prematuramente a morte do homem cordial. Desse

\footnotetext{
${ }^{5}$ F. Nicolazzi (2014, p. 32) alerta, explicitamente, para como a história da historiografia, mesmo em sua função crítica, "acaba também por engendrar memórias disciplinares", afastando-se ou reinventando tradições.

${ }^{6}$ A linha divisória traçada pelo autor não é efetivamente tão simples. Demanda a compreensão da sua redefinição nos âmbitos político e profissional, em que está implicada a segunda edição de RdB. Entre os fundadores, nos anos 40, da Associação Brasileira de Escritores (ABDE) e da Esquerda Democrática (depois Partido Socialista), Buarque de Holanda se engajou também pela profissionalização das letras e humanidades em nosso país - enquanto transitava entre instituições culturais, a crítica literária e a universidade. Discreto, embora resoluto, quanto às mudanças no texto, o prefácio à segunda edição de $R d B$ apresentava, entretanto,
} 
modo, o autor acaba por diminuir a importância, entre outras, de uma potencial análise mais acurada das modificações entre as edições, conforme esboçara Ricardo. A própria mudança acelerada da situação histórica faria o "homem cordial" tombar no abismo do esquecimento:

Com a progressiva urbanização, que não consiste apenas no desenvolvimento das metrópoles, mas ainda e sobretudo na incorporação de áreas cada vez mais extensas à esfera da influência metropolitana, o homem cordial se acha fadado a desaparecer, onde ainda não desapareceu de todo. $E$ às vezes receio sinceramente que já tenha gasto muita cera com o defunto (HOLANDA 1948, p. 54).

A contenda a rigor termina por aí, mas não cessará de ser evocada por Buarque de Holanda. As "Variações sobre o Homem Cordial", de Ricardo, e a resposta em forma de "Carta a Cassiano Ricardo" são anexadas à terceira edição de $R d B$, de 1956. O apêndice poderia servir para "esclarecer um assunto diversamente interpretado pelos críticos que se ocuparam do livro" (HOLANDA 1956 , p. 9). Permanecem os textos da polêmica na quarta edição, de 1963, da Universidade de Brasília (UnB), mas não na subsequente, de 1969, de volta à José Olympio Editora.

Quase 20 anos mais tarde, Buarque de Holanda retomou os autocomentários sobre $R d B$, em situação de grave seriedade. Em abril de 1967, foi convidado a proferir conferência na Escola Superior de Guerra (ESG) do Estado-Maior das Forças Armadas. A conferência integrava um ciclo de discussões intitulado "Elementos básicos da nacionalidade", que afluía para a configuração da Doutrina de Segurança Nacional, grande objetivo da ESG. A inquietação do autor é evidente na seguinte passagem: "[...] convidado a falar-vos do 'homem brasileiro', não se estranhe que deva eu principiar por esta tentativa de autocrítica, incidindo sobre opiniões que provavelmente sugeriram este convite" (HOLANDA 1967, p. 3-4).

Buarque de Holanda então revisitou suas memórias pessoais, a propósito de, retrospectivamente, clarificar os aspectos determinantes da gênese e historicidade da obra. A sua experiência alemã (1929-1930), segundo o que rememorou, havia lhe despertado maior sensibilidade para a percepção dos contrastes entre indivíduos de formações culturais distintas, de modo que procurou tomar distância de um "patriotismo exclusivista" em favor da compreensãoda alteridade.

Ao voltar de minha primeira residência em país estrangeiro, precisamente da Alemanha de logo antes de Hitler, trouxera eu o meu primeiro livro, só muito parcialmente escrito, é certo, mas no essencial quase todo ele pensado. [...] Em nenhum momento, é verdade, deixara eu transparecer em suas páginas qualquer sedução pelos regimes de força. Publicado o livro em 1936, quando andava em maré alta a pregação do integralismo, oferecia ele, ao contrário, uma denúncia inequívoca do fascismo, tanto em suas manifestações europeias como na variante indígena (HOLANDA 1967, p. 2-3).

inequívoca denúncia da "ditadura pessoal de inspiração totalitária" entretempos (HOLANDA 1948, p. 11). O artigo "Novos rumos da sociologia" (1948) também sinaliza tais ajustes na sua trajetória intelectual, quando diz ter sido revisada em segunda edição a ambiçãodo ensaio original (HOLANDA 2011a, p. 514). 
Em seguida, a reconsideração mais importante feita nessa conferência, porque reveladora da razão precisa do desconforto do autor com relação ao seu livro de estreia, é que são - sempre segundo ele mesmo - as próprias contradições presentes no contexto dos anos 1930, de crise das democracias liberais e ascensão dos regimes de força na Europa e no Brasil, que tornam o ensaio por vezes ambíguo e de difícil conclusão: "apenas me pergunto se os argumentos a que recorri para combater essa atração [pelas ditaduras] não pertencem rigorosamente à mesma seara onde outros, na mesma época, foram recolher seus motivos para enaltecê-la" (HOLANDA 1967, p. 3).

Erigia-se, então, um segundo pilar da autocrítica de Buarque de Holanda a RdB.Seguida à polêmica com Cassiano Ricardo, que se concentrava na verdadeira acepção da palavra "cordial", o autor passava agora a melhorsituá-lo em sua historicidade, reconhecendo a proximidade, mas delimitando diferenças para com seus contemporâneos de geração. Ainda uma terceirareconsideração aparece nesta conferência: "em 1936 escrevia eu como ensaísta: mais tarde iria definir-me melhor como historiador" (HOLANDA 1967, p. 3). É interessante percebercomo, aotomar distância do ensaio, ele sugere um marco divisor - o da profissionalização no ofício de historiador em sua trajetória. Podemos inferir que $R d B$, em 1967, eratomado por seu autor como documento de um período particular da historiografia brasileira. ${ }^{7}$ São os estertores do homem cordial.

É notável a proximidade temporal entre a palestra na ESG e o prefácio de 148 Antônio Candido para a quinta edição de $R d B$. Publicado em 1969, mas datado de 1967, "O significado de Raízes do Brasil" consolidou-se como o mais importante aporte orientador e estabilizador da leitura do ensaio, ponto de se tornar ele mesmo um clássico (MONTEIRO 2008, p. 355). Desde então, nunca mais o prefácio deixou de acompanhar o livro nas numerosas edições subsequentes. ${ }^{8}$

Tamanho é o poder de sugestão desse prefácio de 1969, que geralmente se ignora a existência de um anterior, produzido para a quarta edição (1963), que possui a excepcionalidade de não ter sido publicada pela José Olympio Editora. O livro então fez parte dos primeiros números da Coleção Biblioteca Básica Brasileira (v. 10), edição da Universidade de Brasília (UnB), capitaneada por Darcy Ribeiro, algo significativo considerando-se a envergadura não apenas do projeto editorial, de "apresentar o Brasil aos brasileiros", mas também das ambições democratizantes que presidiam a recente fundação da UnB (1962). Segundo consta em depoimento, Buarque de Holanda considera essa a mais importante das edições de $R d B$, devido exatamente ao prefácio de Candido. Dizia ele, na ocasião: "[...] a mais importante foi a quarta edição, da UnB, encomendada pelo Darcy Ribeiro. O prefácio foi feito pelo Antonio Candido, e

\footnotetext{
7 Importa frisar, porém, que o texto lido na ESG teve circulação muito restrita. Foi publicado originalmente como folheto impresso na própria ESG, classificado como documento "reservado". Apenas recentemente o texto veio a público (EUGÊNIO; MONTEIRO 2008, p. 617-637).

8 Os elementos paratextuais exercem forte gravidade em relação ao texto que prolongam. Quanto aos prefácios aqui analisados, "ulteriores" e "alográficos": são escritos por outrem que, valendo-se de sua posição de autoridade no campo específico, recomenda o livro aos novos leitores e lhes orienta a leitura o mesmo vale para os "autocomentários tardios", estes materialmente independentes do texto (GENETTE 1987 , p. 271 e p. 372).
} 
tenho a impressão de que isso deu sorte, porque a partir dali o livro passou a ter muita reimpressão, às vezes duas por ano" (SOUZA 2004, p. 6).

O livro em 1963 já é apontado por Candido como clássico. Mas ainda um livro que se fez clássico tendo subsistido ao tempo e à institucionalização universitária dos estudos históricos: "Este livro, publicado faz quase trinta anos, atravessou facilmente o período mais transformador dos estudos sociais no Brasil e se tornou um clássico" (CANDIDO 1963, p. ix, grifos meus). O homem cordial começa a trilhar o caminho da remição.

Em 1969, Antonio Candido assumia a voz do testemunho de uma geração intelectual, estabelecendo assim um cânone da moderna historiografia brasileira (FRANZINI; GONTIJO 2009, p. 156-7). Ele revisitava as memórias de estudante de sociologia na Universidade de São Paulo (USP) a fim de indicar a marca deixada pela leitura, não apenas de $R d B$, como também de Casa-Grande \& Senzala (1933), de Gilberto Freyre, e Formação do Brasil Contemporâneo (1942), de Caio Prado Jr. Estes livros, que interpretaram o sentido da história brasileira e o caráter singular da brasilidade, ele os considerava como expressivos do radicalismo intelectual surgido da Revolução de 1930, especialmente para os jovens, como ele, de esquerda. Candido se Ihes opunha a obra de Oliveira Vianna, que ao lado deles já parecia defasada, em função dos "preconceitos ideológicos" de que era portadora (CANDIDO 1969, p. xi).

Na conferência de 1967, Buarque de Holanda deixava transparecer sua preocupação relativa ao emaranhado de ideias e propostas que se insinuavam nos anos 1930, ao cogitar se não havia bebido na mesma fonte de autores ligados abertamente ao campo conservador. Em "O significado de Raízes do Brasil", Candido, porém, não tomou conhecimento dessa dúvida ecravou que "a sua inspiração vinha de outras fontes e as suas perspectivas eram diferentes" em relação aos demais (CANDIDO 1969, p. xii).

Candido associava o método de Buarque de Holanda, antes de mais nada, à "nova história social dos franceses" (CANDIDO 1969, p. xiv). Entretanto, a afirmação de um Buarque de Holanda "annaliste" em RdB dificilmente se sustenta. Um olhar perquiridor sobre as notas de pé de página e o índice onomástico - mesmo da quinta edição, e menos ainda em 1936 - é suficiente para percebermos que nenhum dos historiadores franceses desse grupo é citado. Trata-se, fora de dúvida, de uma construção a posteriori (CANDIDO 1969, p. xiv). Em seguida, sim, Candido concedia justo lugar à sociologia da cultura e etnologia alemãs como referências basilares do ensaio, "constituído sobre uma admirável metodologia dos contrários" (CANDIDO 1969, p. xiv).

Após detalhada resenha, capítulo por capítulo do livro, resulta que, para Candido, o ensaio, distante de definições cabais ou soluções imediatas, "impede o dogmatismo e favorece a reflexão de tipo dialético" (CANDIDO 1969, p. xxi). Considerados tais aspectos, soa artificial que, mesmo reconhecendo a "discreta e quase remota" tomada de posição de Buarque de Holanda, Candido assevere, ao cabo e em suma, que o livro se distinguisse tão nitidamente, em 1936, pelo pensamento das condições da vida democrática no Brasil (CANDIDO 1969, p. $x x$ ). Isto não representa necessariamente, como alerta Kennedy Eugênio (2011, 
p. 395), pura invenção, mas é certo que desconsidera as amplas transformações decorridas nas três décadas anteriores - na história do livro, na trajetória de seu autor. Somente desse modo é que fora possível, na sua edição definitiva, entronizar $R d B$ como um "clássico de nascença" (CANDIDO 1969, p. xii).

\section{O homem cordial redivivo (1969-1982)}

Buarque de Holanda concedeu diversas entrevistas de meados da década de $1970 . E m$ seu arquivo pessoal consta que, de um total de trinta entrevistas conservadas desde 1925, dezessete foram realizadas entre 1976 e $1982 .{ }^{9}$ Dessas, são três as temáticas principais, frequentemente entrelaçadas: aposentado da cátedra de História da Civilização Brasileira da USP desde 1969, revisitava a sua trajetória intelectual; comentava a situação política, entre o auge dos "anos de chumbo" e o início do processo de "abertura" do regime militar; e, ainda, a própria história do Brasil, notadamente a história política, à qual se dedicoudesde Do Império à República (1972). Em revisitando sua trajetória, o historiador voltava a se ocupar de suas insatisfações com relação a $R d B$, no essencial as mesmas externadas em 1948 e $1967 .{ }^{10}$ É na rememoração de Buarque de Holanda, após a edição definitiva, que encontra abrigo o "homem cordial redivivo", tensionado pelas contradições entre a sua agonia e remição.

Observamos, nessas recordações, a autocrítica ainda muito atrelada à sua intenção com o uso da palavra "cordial", lado a lado à atenuação da "morte do homem cordial", pela via da imersão na historicidade da obra. Temos também que subjaz uma inquietação política com relação à autocrítica do ensaio. Não era, então, apenas autocelebração; o componente comemorativo ficava por conta de outros atores, seus próximos. ${ }^{11}$ Efetivamente, acontece que, como o seu autor mesmo admitirá, pesava sobre ele a crítica de haver sustentado uma "ideologia do homem cordial". A "crítica das ideologias"era candente entre os jovens historiadores da historiografia na universidade brasileira, que desconfiavam dos"intérpretes do Brasil" da década de 1930, aproximando Freyre, Buarque de Holanda e outros da mesma geração: "como não possuem explícita uma teoria das classes sociais no Brasil, os ideólogos da cultura brasileira podem se permitir falar do povo com tal nível de generalização que toda a história fica nivelada numa superfície com poucas manifestações de tensão" (MOTA 2010, p. 35). A escrita de si de Buarque de Holanda em boa medida responde a essas pressões, quando então se vê ameaçada sua posição na memória disciplinar. Mesmo o debate atual sobre as edições de $R d B$ pouco dialoga com essas críticas abertas há quatro décadas (CARVALHO 2017, p. 189-211). ${ }^{12}$

\footnotetext{
9 Para Arfuch, com as novas configurações do espaço público no século 20, a midiatização e suas tecnologias, a entrevista ganhou em importância enquanto forma de escrita de si (ARFUCH 2010, p. 117).

${ }^{10}$ Algumas dessas entrevistas foram reunidas em livro. O organizador destaca a "curiosidade quase desastrosa sobre o homem cordial", mas reproduz: "As poucas (e boas) palavras do mestre aqui compiladas ajudam a desfazer tal engano" (MARTINS 2009, p. 11).

${ }_{11}$ Paul Ricœurnos dá a entender que o plano intermediário de referência entre memória pessoal e coletiva, entre o si mesmo e o(s) outro(s), se encontra nos próximos, aqueles "outros privilegiados", entre o indivíduo e a comunidade de pertença (RICFUR 2000, p. 161-3). Entre os pares intelectuais, coube principalmente a Candido a atestação do discurso de si de Buarque de Holanda.

12 Entre eles, principalmente C. G. Mota (1977), com quem Buarque de Holanda polemizou sobre sua concepção, pioneira, diga-se, de escrita da história (HOLANDA 1973). Outros autores aceitavam sem maiores
} 
Em 1976, Buarque de Holanda concedeu entrevista para as então inovadoras "páginas amarelas" da revista Veja, sob título "A democracia é difícil: as observações e as conclusões de um especialista com base no exame da história". Em breve introdução, o jornalista traçou resumidamente o percurso e o perfil do historiador - pululavam nas entrevistas as referências ao "grande tripé básico da cultura brasileira no século XX", e ao "pai do Chico, como adora ser chamado" (COELHO; HOLANDA 1976, p. 3). Buarque de Holanda se esforça em redirecionar o sentido geral do ensaio, quando indagado sobre o que ele mudaria no livro, passados exatos 40 anos de sua primeira edição.

Eu escrevi dois de seus capítulos na Alemanha, quando lá morei, entre 1928 [sic] e 1931. A ideia básica era de que nunca houve democracia no Brasil e de que necessitávamos de uma revolução vertical, que realmente implicasse a participação das camadas populares. Nunca uma revolução de superfície, como foram todas na história do Brasil, mas uma que mexesse mesmo com toda a estrutura social e política vigente (COELHO; HOLANDA 1976, p. 3).

Ao mesmo tempo em que afirmava o caráter revolucionário do livro, Buarque de Holanda procurava tomar distância dele, contradição que não passou despercebida por Kennedy Eugênio. Contudo, eleminora as críticas da historiografia de 1970 como meras reprises da autocrítica do ensaio, fundador que seria Buarque de Holanda, em sua visão, da própria crítica ao livro de 1936 (EUGÊNIO 2011, p. 451). Sigamos, um passo adiante disso, que indica, a meu ver, o peso de tais considerações autocríticas sobre a recepção acadêmica da obra: as reprises parecem, antes, as rememorações de Buarque de Holanda em retorno às contestações. Notaremos ainda que, a exemplo da conferência na ESG, o livro está "superado e datado", o que, pela lembrança da historicidade da obra, nuança a severidade da negação de 1948 diante de Cassiano Ricardo sobre "a morte do homem cordial".

Hoje, eu não me aventuraria mais a uma empreitada dessa espécie. Simplesmente porque os tempos são outros [...]. Há pouco tempo uma editora francesa, a Gallimard, me propôs a tradução de "Raízes do Brasil". Pediram-me também um ensaio, que seria publicado na edição francesa, atualizando minhas ideias. Tentei, mas acabei desistindo. O livro está superado e plenamente datado. Não tem sentido reescrever eternamente a mesma obra (COELHO; HOLANDA 1976, p. 3-4). ${ }^{13}$

Mais adiante, na mesma entrevista, Buarque de Holanda repetia o argumento, colocado pela primeira vez na ESG, sobre as distâncias que procurou

\footnotetext{
dificuldades a autocrítica de Buarque de Holanda. D. M. Leite (1969, p. 323) entendia o homem cordial como "descrição intuitiva do brasileiro de classe alta", mas considerava RdBum livro "isolado" no conjunto da obra buarqueana. Ainda mais diretamente, A. Marson (1971, p. 528) atenuava as críticas: "o próprio historiador de Raízes do Brasil já se ocupou à saciedade na demonstração do sentido textual do conceito de 'cordial'".

13 Arthur Assis, ainda que pouco preocupado com a crítica do testemunho, considera a importância dessa rememoração autocrítica, de distanciamento do ensaio: "Nesse contexto de entusiasmo geral em torno de Raízes do Brasil, mencionar que o próprio autor, 40 anos após a publicação do livro, o qualificou como 'superado e completamente datado' [...] corresponde a remar contra uma forte maré intelectual" (ASSIS 2010, p. 93).
} 
tomar do ensaísmo de interpretação em favor da pesquisa histórica. "[...] 0 livro ficou no nível do ensaio. Não sou contra a ensaística ou a interpretação, mesmo hoje. Mas a pesquisa deve ser rigorosa e exaustiva" (COELHO; HOLANDA 1976, p. 6). Todavia, essa entrevista apresenta uma resposta, essa sim, muito contundente à crítica ideológica na historiografia. Buarque de Holanda mobiliza a própria historicidade do pensamento histórico, em reflexão algo afim aos desenvolvimentos posteriores da epistemologia da história:

\begin{abstract}
A atual geração de historiadores considera a ideologia um pensamento falso. Mas eu pergunto: será possível assumir uma ideia que seja válida? Cada um de nós tem, no fundo, uma certa ideologia, um certo conceito de tempo. Para transcender isso, somente um gênio. E não devemos ficar externamente de braços cruzados à espera desse ser excepcional, devorador de ideologias, que assumiria o ponto de vista da eternidade (COELHO; HOLANDA 1976, p. 6)
\end{abstract}

No ano seguinte, 1977, o Jornal do Brasil promoveu uma enquete sobre a responsabilidade dos intelectuais na orientação do destino nacional. Buarque de Holanda disse não se ver como grande mentor da opinião pública brasileira- a resposta é indício de tal reconhecimento -, pois que nenhum intelectual seria capaz de um tal feito sozinho. Advertência feita, pôs-se o autor a ruminar as mesmas conhecidas considerações a propósito de $R d B$.

Entre muitas discussões, críticas de que se tratava da apologia de uma ideologia burguesa, surgiu até um livro do Cassiano Ricardo, que interpretou-a em sentido diverso do que eu lhe dava. [...] Ora, é bom lembrar que a cordialidade não é só um estado de benevolência. Pode ser também de malevolência. [...] Mas eu mesmo, na resposta a Cassiano Ricardo, cheguei a dizer que o homem cordial morreu e já se tem gasto muita cera para esse defunto (JORNAL do Brasil 1977, p. 1).

Desse discurso, importa observar atentamente a curiosa associação entre o conflito com Cassiano Ricardo e a crítica ideológica, crítica essa que somente agora se levantava, e que não se reduzia às suas intenções no uso da expressão "cordial". Considerar a resposta enviesada de Buarque de Holanda fortalece a hipótese de que a repetição da contenda com Cassiano Ricardo visava resguardar $R d B$ de outras possíveis contestações.

No ano seguinte, o historiador concedeu algumas importantes entrevistas sobre o regime militar e o início do processo de abertura. Naquele 1978 ele passava a falar sobre o assunto de forma mais enfática, agora na condição de vice-presidente do Centro Brasil Democrático (Cebrade), fundado por Oscar Niemeyer. Não deixou de lado, porém, a rememoração acerca de seu livro de 40 e poucos anos. Ele ainda era requisitado pelos jornais como "explicador do Brasil", pois: "Como entender este país? Foi o que Sérgio Buarque de Holanda buscou responder nesta entrevista e quando escreveu um livro clássico da nossa historiografia: 'Raízes do Brasil', publicado nas vésperas do Estado Novo, mas atual porque ainda não superamos nossas raízes" (CARDOSO; HOLANDA 1978, p. 3). O jornalista da Folha de S. Paulo, RdB em mãos e munido de longo 
arsenal de questões, encontrou um Buarque de Holanda muito à vontade, de pantufas "com o contraforte pisado" e "caixa de cigarros em mãos". Tudo isto, bem ao largo da importância que Ihe era atribuída: "o Velho Mestre é a memória viva do país" (CARDOSO; HOLANDA 1978, p. 3). Quase desnecessário, desse comentário, sublinhar o papel conferido a Buarque de Holanda no plano da memória social, ${ }^{14}$ em função das novas lutas democráticas (NAPOLITANO 2014, p. 315), para as quais $R d B$ era convocado a orientar o sentido.

Exemplo disso, Buarque de Holanda recebia em 1980 a consagração definitiva com o troféu "Juca Pato" de "Intelectual do Ano", concedido pela União Brasileira de Escritores (UBE) por Tentativas de Mitologia (1979), último livro publicado em vida. A premiação na UBE, em 1980, comportou manifestação política. Buarque de Holanda (1980), de modo a conferir profundidade e coerência a seu posicionamento, lembrou o seu engajamento no I Congresso de Escritores (1945), da então ABDE, contra a ditadura do Estado Novo. Enquanto Mota (1980), no jornal da UBE, manifestou-se contra aquele "desfile de unanimidades", Candido (1980) afirmou que o prêmio consagrava "a mais completa organização de historiador do Brasil". Coordenada pela afirmação de sua "vocação principal, de historiador" (HOLANDA 1979, p. 32), estabilizava-se em Tentativas de Mitologia uma "identidade narrativa" de Buarque de Holanda - defendo que o livro representa efetivamente sua autobiografia intelectual. Segundo o conceito ricœuriano, o autor reconhece a si mesmo pela narrativa de si, harmonizada a mudança temporal na coerência de uma vida, e pelo diálogo com a diferença, o que é bastante pertinente para análise de Tentativas de Mitologia: antologia de antigas críticas (1940-1950) principalmente historiográficas, cujos alvos primeiros eram Vianna e Freyre, precedida de um "ensaio autocompreensivo". A própria vida, enfim, "um tecido de histórias narradas" (RICEUR 1985, p. 356). A propósito de Raízes, contamos aí com uma narrativa da gênese do livro, explicativa dos caminhos e desvios de seu projeto original. A compreensão histórica sobre a passagem de Buarque de Holanda pela Alemanha, vista como o elo entre o modernismo e $R d B$, temas essenciais de Tentativas de Mitologia, se nutre quase exclusivamente das rememorações, mesmo na historiografia especializada. ${ }^{15}$

Recomecei a ler, e recomecei mal, enfronhando-me agora em filosofias místicas e irracionalistas (Klages, etc.), que iam pululando naqueles últimos anos da República de Weimar e já às vésperas da ascensão de Hitler [...]. Foi só depois de conhecer as obras de críticos ligados ao

\footnotetext{
${ }_{14}$ Ato pessoal de lembrança, a rememoração se insere na dimensão pública pelas relações que entretece com as comemorações. Estas se dirigem, por sua vez, a grupos sociais portadores de uma memória, que "preside as relações intersubjetivas e deriva das mesmas" (SILVA 2002, p. 429).

${ }^{15}$ Assim, para ficarmos com um único exemplo, em Roberto Vecchi (2008, p. 369): "é o próprio Sérgio que atesta o elo estrito entre o momento modernista e a concepção de Raízes do Brasil". Vecchi então cita, como se autoexplicativa, resposta de Buarque de Holanda a Richard Graham (1982), sobre RdB como ruptura com o passado. Esses apontamentos de modo algum servem para censurar os trabalhos em questão (de Eugênio, Vecchi ou Assis), que são referenciais, senão para o reconhecimentoda incidência de estratagemas memoriais sobre a fortuna crítica - sem também, de minha parte, reivindicar autonomia em relação à memória. Em dossiê comemorativo dos oitenta anos de RdB, na Revista Brasileira de História (n. 73), Sérgio da Mata (2016) estudou as leituras e apropriações da "constelação de autores conservadores" pelo jovem autor de $R d B$, o que de certa forma questiona essa rememoração da temporada alemã.
} 
círculo de Stefan George, especialmente de um deles, Ernst Kantorowicz, autor de um livro sobre Frederico II (Hohenstaufen) que, através de Sombart, pude afinal "descobrir" Max Weber, de quem ainda guardo as obras então adquiridas. Os livros de Weber e um pouco as lições de Meinecke, em Berlim, indicando-me novos caminhos, deixarão sua marca na minha Teoria da América. Quando voltei ao Brasil em 1931 trazia um calhamaço de suas 400 páginas. Dele tirei o essencial para um estudo histórico [Corpo e Alma do Brasil, 1935] encomendado [...]. Alguns anos depois saiu o meu livro, com quase dois capítulos tomados a esse artigo [...], já se chamava Raízes do Brasil, nome que ainda conserva hoje, na sua $12^{a}$ edição (HOLANDA 1979, 29-30).

Uma comitiva de pesquisadores esteve no MIS em 1981, para gravar depoimento do historiador no projeto "Estudos Brasileiros", coordenado por Ernani S. Bruno. Em 2004 foi publicado pela revista Novos Estudos (Cebrap), com o título "Corpo e Alma do Brasil", por iniciativa de Laura de Mello e Souza (2004, p. 3-14). RdB, é claro, ocupou boa parte das atenções. A repetição das mesmas elucubrações já conhecidas indica a presença de algo de incômodo nessa memória.

O livro foi publicado em 1936, uma época muito dura para o Brasil, quase tão dura quanto a atual. E nele afirmo que uma revolução no Brasil não pode ser uma revolução de superfície: teria de ser uma revolução que levasse em conta todos os elementos mais aptos que estão por baixo. 0 fato é que não pensei mais nesse assunto. Tanto que as novas edições têm saído sem mudança. Só agora, que se tem falado muito naquela questão do homem cordial - eu tenho sido muito criticado por isso -, resolvi pedir que na próxima edição eles incluíssem uma parte da minha polêmica com o Cassiano Ricardo. Cassiano implicava com o termo "cordial". Para ele, o correto seria "homem bom". Mas minha ideia não era fazer nenhuma avaliação ética. [...] Antonio Candido sugeriu que eu excluísse a polêmica, pois publicá-la seria dar crédito demais ao Cassiano. Pode ser, mas a minha parte achei que devia publicar. Ao menos assim me defendo um pouco (SOUZA 2004, p. 10, grifos meus).

O comentário acima explica a reaparição abrupta da "Carta a Cassiano Ricardo" na décima quarta edição (1981). Requentada anos depois pelas ponderações tardias de Buarque de Holanda, o affaire Ricardo não teria razão de reaparecer senão atrelado aos estratagemas da memória. O mais importante: perceba-se o desconforto do autor com a crítica dos anos 1970. Contudo, mobilizar o debate de 1948 sobre a etimologia da cordialidade, era, como já se argumentou aqui, insuficiente para dar conta da crítica deuma "ideologia conservadora". Já confissão de alguns expedientes editoriais e da estreita cumplicidade entre o autor e o prefaciador, Antonio Candido, é mais um indício das estratégias memoriais. Note-se, ainda, que apenas muito discretamente Buarque de Holanda se refere às mudanças no texto; menos ainda fez menção ao teor ou à profundidade das mesmas, que o debate atual minuciosa e categoricamente evidencia.

No mesmo ano, Buarque de Holanda concedia nova entrevista, conduzida por Richard Graham, para a Hispanic American HistoricalReview (HAHR). Buarque de Holanda, ciente de seu provável caráter testamentário, teve muito 
cuidado com ela, revisou-a "tin-tin por tin-tin", segundo Graham (CARTA de Graham a Buarque de Holanda, 1981). Indagado sobre o livro preferido de sua autoria, reconheceu que o ensaio de 1936 ganhou maior repercussão, mas revelou preferência por Visão do Paraíso (1959), trabalho de historiador, tese que Ihe valeu a cátedra na USP, comentando o aprofundamento da pesquisa nas edições subsequentes (1968 e 1977) e a preparação de caprichada tradução para o espanhol (1987). RdB, por sua vez, Buarque de Holanda considerava como "mera coleção de ensaios" (GRAHAM 1982, p. 10).

\section{Memória da obra: historiografia e política}

Para Judith Schlanger (2008, p. 170), não coincide a data de aparição de uma obra com a sua "entrada na memória", que geralmente acontece mais tarde e repetidas vezes. As reediçõessão novas inscrições de uma obra no tempo. Divisaremos, então,que,ao lado da autocrítica de Buarque de Holanda,também as comemorações de $R d B$, em reedições especiais, visavam, no período em tela, prolongar o sentido da obra em direção à cultura política ou memória coletiva da redemocratização, assim como inscrevê-la em determinada tradição historiográfica.

Entre a edição definitiva, de 1969, e 1986, ano em que se comemorou o "Jubileu de Ouro" de $R d B$, contamos nada menos que onze edições. Os pretextos comemorativos embalaram a publicação de algumas dentre tão numerosas edições e, destarte, contribuíram para a reafirmação do clássico da modernidade brasileira e da memória em torno do historiador. Também pela comemoração, portanto, $R d B$ recobrava nova vida. O que não se poderia era supor, como sugeriu Buarque de Holanda, que o prefácio de Antonio Candido simplesmente "deu sorte" para o bom êxito tardio do livro. A parceria intelectual entre os dois vai, afinal,muito "além de um prefácio", como demonstra Thiago Nicodemo (2016) em um "esboço de biografia cruzada".

Apenas dois anos depois da edição definitiva (1969), temos uma nova em 1971, a sexta. O editor José Olympio enviou, do Rio de Janeiro, uma carta para "o grande e querido editado Sérgio Buarque", em setembro de 1971, dando notícia e prestando satisfações da "sexta edição do seu já clássico 'Raízes do Brasil' edição comemorativa dos 35 anos do livro". O editor lhe informava a impressão incomum de seis mil exemplares, dos quais dois mil seriam encaminhados ao Instituto Nacional do Livro (INL), e os quatro mil restantes seriam distribuídos entre as livrarias do país (CARTA de José Olympio a Buarque de Holanda, 1971).

Em 1976, o livro já somava sua décima edição, mesmo que a crise econômica de 1973 tivesse desestabilizado o mercado editorial brasileiro. Graças às amizades pessoais de José Olympio, evitou-se que a sua casa editora fosse vendida para estrangeiros, mas o Banco Nacional do Desenvolvimento Econômico (BNDE) assumiu o seu controle (HALLEWELL 2012, p. 532-5). O novo conselho editorial determinou a convenção de (re)editar "obras consagradas", obedecendo interesses puramente mercadológicos. O parecer de Candido quanto ao "clássico de nascença" inclusive virara já slogan publicitário: na própria capa do livro se encontrava a expressão, entre aspas e assinada pelo crítico, a partir da décima edição. Na folha de rosto, abaixo do título, a inscrição: 
"Nona edição comemorativa do Jubileu de Esmeralda do livro e da coleção". A Coleção Documentos Brasileiros havia principiado justamente por $R d B$, em 1936. Em função disso, à "Nota da Editora: dados biobibliográficos do autor" e à "história bibliográfica de Raízes do Brasil", que acompanhavam o livro desde a quinta edição de 1969, outro componenteparatextual era incluído, "Os 40 anos de 'Raízes do Brasil' e da Coleção Documentos Brasileiros", por Afonso Arinos de Melo Franco. Quadragenária, a Coleção atingia o status de "um dos maiores monumentos da cultura nacional" (FRANCO 1976, p. xi). Sobre RdB, Arinos asseverou que ele começava sua carreira com "um livro definitivo", o que reforçava a impressão de um clássico desde sempre.

Quatro anos após o decesso de Buarque de Holanda, 1986 ficou marcado, na história da sua memória, por um considerável número de comemorações relevantes. $R d B$ completava seu cinquentenário, e uma edição mais que especial, comemorativa do Jubileu de Ouro, fora preparada para a ocasião. Foitambém o ano da inauguração da "Biblioteca Sérgio Buarque de Holanda"na Unicamp instituição que incorporou a seu patrimônio o legado buarqueano, como parte de um projeto de preservação da "memória científica nacional" (COSTA 1986) - e da primeira publicação original póstuma, o livro O Extremo Oeste, organizado pelo discípulo José Sebastião Witter. Esses eventos se articulam, de modo que se pode falar em 1986 de um complexode celebrações à memória de Buarque de Holanda.

A décima oitava edição (1986) de $R d B$, comemorativa do Jubileu de Ouro, aparecia incrementada de novos e ricos elementos paratextuais. A "Nota da 156 Editora" com os dados biobibliográficos do autor extrapolava a barreira da morte para registrar alguns eventos comemorativos que se seguiram. É acrescido um belo álbum de imagens de Buarque de Holanda acompanhado de outros intelectuais, amigos e familiares. Outro componente importante era o texto do ensaísta Alexandre Eulalio, pronunciado na solenidade de inauguração da biblioteca na Unicamp.

Mas o que intriga é a presença inédita de dois outros documentos. Trata-se da tradução das cartas enviadas a Buarque de Holanda em 1948 por historiadores franceses dos Annales, Lucien Febvre e Fernand Braudel. Esse último agradecia-lhe o envio da segunda edição de $R d B$ e elogiava "suas preocupações de historiador, tão próximas das nossas" (HOLANDA 1986, p. xix-xx). Lucien Febvre, por sua vez, convidava oficialmente Buarque de Holanda a ministrar cursos na VIa. Seção da "École Pratique des Hautes Études" (HOLANDA 1986, p. xx). Foi apenas em fins dos anos 1940 que Buarque de Holanda estreitou relações com os historiadores franceses. Em momento de redefinições do campo de estudos brasileiros e de virada em sua própria trajetória e concepção de história, Buarque de Holanda rendeu-Ihes tributos em ensaios historiográficos (HOLANDA 2011b, p. 18-21).

Deve-se considerar, portanto, o uso dessas cartas. Elas aí estão publicadas porque a organização e inauguração do acervo pessoal o possibilitava. ${ }^{16}$ Considerando a reflexão um pouco apressada de Candido (1969), para quem $R d B$ é impregnado da "história social dos franceses", a recuperação dessas cartas parece acorrer em reforço de tal afirmação. Houve, com isso, efetivamente um

${ }_{16}$ Para conhecimento pormenorizado do processo de constituição do acervo, ver SILVA 2015. 
esforço por inscrever o livro na tradição historiográfica dos Annales, amplamente reconhecida como a mais inovadora e importante no século 20.

Candido esteve bem próximo da concepção dessa edição comemorativa do Jubileu de Ouro, com um post-scriptum ao prefácio de 1969. Considerese, entretempos, o engajamento do historiador na fundação do Partido dos Trabalhadores (PT), em 1980, e seu projeto democratizante de inclusão e redução das desigualdades sociais. O objetivo de Candido era não apenas reforçar, mas tornar ainda mais explícita a "mensagem política" de $R d B$, agora em andamento a "Nova República". Esse post-scriptum acompanha todas as edições desde então:

\begin{abstract}
Cinquenta anos depois Raízes do Brasil continua um grande livro, cheio de sugestões e originalidade. [...] Falo do que se poderia chamar o "radicalismo potencial das classes médias", que no caso de Sérgio adquire timbre diferenciador, ao voltar-se decididamente para o povo. Por isso, repito com realce o que escrevi no prefácio de 1967: uma das forças de Raízes do Brasil foi ter mostrado como o estudo do passado, longe de ser operação saudosista, modo de legitimar estruturas vigentes, pode ser uma arma para abrir caminho aos grandes movimentos democráticos integrais [...] (CANDIDO 1986, p. li-lii).
\end{abstract}

Já avançada a década de 1990 - cito para sugerir a continuidade e as apropriações da memória da obra -, Candidovoltará a se ocupar de $R d B$, no seminário "Sérgio Buarque de Holanda e o Brasil", promovido pela Fundação Perseu Abramo (PT), em reafirmando a imagem do "democrata radical" (CANDIDO 1998, p. 88).

\title{
Conclusão
}

Podemos, enfim, reter dessa pequena "autobiografia de $R d B$ " que a escrita de si de Buarque de Holanda e os estratagemas memoriais convergem, em reforço das revisões no texto, para areconfiguração do livro em novo horizonte, o da redemocratização. Sob a égide da memória, e em função das questões do tempo presente, portanto, $R d B$, após a edição definitiva, rememorado e comemorado,era reposicionado na cultura política e reafirmado na história da história.

A autocrítica parte da verdadeira acepção da cordialidade, da imersão na historicidade da obra, passandopeladelimitação da identidade historiadora, até a afirmação dos posicionamentos político sem favor da "revolução vertical", vinculados esses a $R d B$. A proximidade de Antonio Candido, não apenas nos prefácios, mas também na atestação do discurso de si de Buarque de Holanda, fornece amparo aos ajustes internos ao texto e procura orientar sua leituraem sentido progressista. Por fim, assucessivas comemorações do ensaio em reedições especiais, acrescidas de rico material relativo à história do livro, muito contribuem paraa atualizaçãodamemória da obra.

Ao alcançar hoje oito décadas de existência, $R d B$ frequentemente ainda é evocado, considerando os descaminhos da democracia entre nós, nos debates sobre o Brasil, seu passado e futuro. Talvez mais do que nunca, ou pelo menos com maior grau de sofisticação, favorecida pelas condições do campo, é debatido na história da historiografia. 


\section{Referências}

ARFUCH, L. El espaciobiográfico. Dilemas de lasubjetividad contemporánea. Buenos Aires: FCE, 2010.

ASSIS, A. A teoria da história como hermenêutica da historiografia: uma interpretação de Do Império à República, de Sérgio Buarque de Holanda. Revista Brasileira de História, v. 30, n. 59, p. 91-120, 2010.

CANDIDO, A. Prefácio. In: HOLANDA, S. B. Raízes do Brasil. 4. ed. Brasília: Ed. UnB, 1963, p. ix-xi.

. O significado de Raízes do Brasil. In: HOLANDA, S. B. Raízes do Brasil. 5. ed. Rio de Janeiro: José Olympio, 1969, p. xi-xxii.

. As tentativas de mitologia de Sérgio Buarque de Holanda. O Escritor. v. 1, n. 6, s.p., 1980.

Post-scriptum. In: HOLANDA, S. B. Raízes do Brasil. 18. ed. Comemorativa do Jubileu de Ouro. Rio de Janeiro: José Olympio, 1986, p. li-lii.

A visão política de Sérgio Buarque de Holanda. In: CANDIDO, A. (Org.) Sérgio Buarque de Holanda e o Brasil. São Paulo: Perseu Abramo, 1998, p. 81-88.

CARDOSO, J. Que país é este? Entrevista com Sérgio Buarque de Holanda. Folha de São Paulo, p. 3, 30 abr. 1978.

CARTA de José Olympio a Sérgio Buarque de Holanda. Rio de Janeiro, 24 fev. 1981.

CARTA de Richard Graham a Sérgio Buarque de Holanda. Rio de Janeiro, 24 mai. 1981.

CARVALHO, R. G. Sérgio Buarque de Holanda, do mesmo ao outro: escrita de si e memória (1969-1986). Tese (Doutorado em História) - Universidade Federal do Paraná, Curitiba, 2017.

CASTRO ROCHA, J. C. Raízes do Brasil: biografia de um livro-problema. In: MARRAS, S. (Org.). Atualidade de Sérgio Buarque de Holanda. São Paulo: Edusp; IEB, 2012, p. 19-39.

COELHO, J. M. A democracia é difícil: entrevista com Sérgio Buarque de Holanda. Veja, n. 386, p. 3-6, 28 jan. 1976.

DOSSE, F. "L'écriture de soi: Essais d'ego-histoire". In: Pierre Nora: homo historicus. Paris: Perrin, p. 389-396.

EUGÊNIO, J. K. Ritmo espontâneo: organicismo em Raízes do Brasil de Sérgio Buarque de Holanda. Teresina: EDUFPI, 2011.

FELDMAN, L. Um clássico por amadurecimento: Raízes do Brasil. Revista Brasileira de Ciências Sociais, v. 28, n. 82, p. 119-140, 2013. 
FRANCO, A. A. M. Os 40 anos de "Raízes do Brasil" e da Coleção Documentos Brasileiros. In: HOLANDA, S. B. Raízes do Brasil. 9. ed. Rio de Janeiro: José Olympio, 1976, p. xi-xii.

FRANZINI, F.; GONTIJO, R. Memória e historiografia no Brasil: a invenção de uma moderna tradição, anos 1940-1960. In: SOIHET, R. et al. (Org.). Mitos, projetos e práticas políticas: memória e historiografia. Rio de Janeiro: Civilização Brasileira, 2009, p. 141-160.

GARCIA, P. Les présents de I'historien. Paris: Publications de la Sorbonne, 2014.

GENETTE, G. Seuils. Paris: Éditions du Seuil, 1987.

GRAHAM, R. An Interview with Sérgio Buarque de Holanda. The Hispanic American Historical Review, v. 62, n. 1, p. 3-17, 1982.

HALLEWELL, L. O livro no Brasil: sua história. 3. ed. São Paulo: Edusp, 2012.

HOLANDA, S. B. Prefácio à $2^{a}$ edição. In: Raízes do Brasil. 2. ed. Rio de Janeiro: José Olympio, 1948, p. 11-12.

. Carta a Cassiano Ricardo. Colégio - revista de cultura e arte, ano I, n. 3, p. 52-54, 1948.

. Novos rumos da Sociologia [1948]. In:

Escritos Coligidos:

livro I, 1920-1949. Organização de Marcos Costa. São Paulo: Ed. Unesp; Fundação Perseu Abramo, 2011a, p. 513-517.

Apologia da história [1950]. In:

Escritos Coligidos: livro

II, 1950-1979. Organização de Marcos Costa. São Paulo: Unifesp; Perseu Abramo, 2011b, p. 18-21.

- Prefácio à $3^{a}$ edição. In: - Raízes do Brasil. 3. ed. Rio de Janeiro: José Olympio, 1956, p. 9.

Elementos básicos da nacionalidade: o homem. Rio de Janeiro: Escola Superior de Guerra, 1967.

- Sobre uma doença infantil da historiografia [1973]. In:

Escritos Coligidos: livro II, 1950-1979. Org. Marcos Costa. São Paulo: Ed. Unesp; Perseu Abramo, 2011b, p. 419-434.

. Tentativas de Mitologia. São Paulo: Perspectiva, 1979.

. Os dias de hoje lembram os de 45 . O Escritor, v. 1, n. 4, p. 4, 1980 b.

. Raízes do Brasil. 18. ed. Comemorativa do Jubileu de Ouro. Rio de Janeiro: José Olympio, 1986.

Encontros. Org. R. Martins. Rio de Janeiro: Beco do Azougue, 2009.

. Raízes do Brasil. Edição crítica. Org. P. M. Monteiro e L. M. Schwarcz. São Paulo: Companhia das Letras, 2016. 
JORNAL DO BRASIL. Qual o poder da inteligência? Rio de Janeiro, Caderno B, p. 1, 2 mai. 1977.

LEITE, D. M. O caráter nacional brasileiro: história de uma ideologia. $2^{\mathrm{a}}$ ed. São Paulo: Pioneira, 1969.

MARSON, A. Sobre a ideologia do caráter nacional: uma revisão. Revista de História, n. 86, p. 513-528, 1986.

MATA, S. Tentativas de (des)mitologia: revolução conservadora em "Raízes do Brasil". Revista Brasileira de História, v. 36, n. 73, 2016, p. 63-87.

MONTEIRO, P. M. Uma tragédia familiar. In: KENNEDY, E.; MONTEIRO, P. M. (Org.). Sérgio Buarque de Holanda: Perspectivas. Campinas: Ed. Unicamp; Rio de Janeiro: EdUERJ, 2008, p. 349-361.

MOTA, C. G. Os fazendeiros do ar [1977]. In: História e contrahistória. São Paulo: Globo, 2010, p. 31-39. . Uma visão ideológica. O Escritor, v. 1, n. 5, s.p. , 1980.

MÜLLER, B. L'opération historiographique chez P. Ricœur ou le statut de I'histoire dans l'épistémologie. In: MÜLLER, B. (Dir.) L'histoire entre mémoire et épistémologie: autour de P. Ricœur. Lausanne: Payot, 2005, p. 183-203.

NAPOLITANO, M.1964: história do regime militar brasileiro. São Paulo: Contexto, 2014.

160 nicodemo, T. L. Os planos de historicidade na interpretação do Brasil de Sérgio Buarque de Holanda. História da Historiografia, n. 14, p. 44-61, 2014.

- Para além de um prefácio: democracia e ditadura no diálogo entre Antonio Candido e Sérgio Buarque de Holanda. Revista Brasileira de História, v. 36, n. 73, p. 159-180, 2016.

NICOLAZZI, F. História da historiografia e temporalidades: notas sobre tradição e inovação na história intelectual. Almanack, n. 7, p. 27-32, 2014.

POPKIN, J. History, historians \& autobiography. Chicago: The University of Chicago Press, 2005.

COSTA, P. R. Alocução do Prof. Dr. Paulo Renato Costa, por ocasião da inauguração da Biblioteca SBH na Unicamp. Campinas, p. 2, 12 ago. 1986.

RICARDO, C. Variações sobre o homem cordial. Colégio - revista de cultura e arte, ano I, n. 2, p. 38-59, 1948.

RICFUR, P. Temps et Récit. Paris: Seuil, 1985. t. III.

La mémoire, I'histoire, I'oubli. Paris: Seuil, 2000.

SCHLANGER, J. La mémoire des œuvres. Lagrasse: Verdier, 2008.

SARTRE, J. P. Les mots. Paris: Gallimard, 1964.

SILVA, H. R. "Rememoração"/Comemoração: as utilizações sociais da memória. Revista Brasileira de História, v. 22, n. 44, p. 425-438, 2002. 
SILVA, R. P. A morte do homem cordial: trajetória e memória na invenção de um personagem (Sérgio Buarque de Holanda, 1902-1982). Tese (Doutorado em História) - Universidade Estadual de Campinas, Campinas, 2015.

SOUZA, L. M. Corpo e Alma do Brasil: entrevista de Sérgio Buarque de Holanda [1981]. Novos Estudos CEBRAP, n. 69, p. 3-14, 2004.

VECCHI, R. Contrapontos à brasileira: Raízes do Brasil e o jogo das metáforas. In: KENNEDY, E.; MONTEIRO, P. M. (Org.). Sérgio Buarque de Holanda: Perspectivas. Campinas: Ed. Unicamp; Rio de Janeiro: EdUERJ, 2008, p. 363-384. 